\title{
Comparison of Steroid Hormone Hydroxylations by and Docking to Human Cytochromes P450 3A4 and 3A5
}

\author{
Toshiro Niwa ${ }^{1, *}$, Kanae Narita ${ }^{1}$, Ayaka Okamoto $^{1}$, Norie Murayama $^{2}$, and Hiroshi Yamazaki ${ }^{2}$ \\ ${ }^{1}$ School of Pharmacy, Shujitsu University, 1-6-1 Nishigawara, Naka-ku, Okayama 703-8516, Japan. ${ }^{2}$ Laboratory of Drug \\ Metabolism and Pharmacokinetics, Showa Pharmaceutical University, 3-3165, Higashi-Tamagawa Gakuen, Machida, \\ Tokyo 194-8583, Japan
}

Received, May 13, 2019; Revised, July 18, 2019; Accepted, July 19, 2019; Published, July 21, 2019.

\begin{abstract}
Purpose: Hydroxylation activity at the 6 6 -position of steroid hormones (testosterone, progesterone, and cortisol) by human cytochromes P450 (P450 or CYP) 3A4 and CYP3A5 and their molecular docking energy values were compared to understand the catalytic properties of the major forms of human CYP3A, namely, CYP3A4 and CYP3A5. Methods: Testosterone, progesterone, and cortisol 6ß-hydroxylation activities of recombinant CYP3A4 and CYP3A5 were determined by liquid chromatography. Docking simulations of these substrates to the heme moiety of reported crystal structures of CYP3A4 (Protein Data Bank code ITQN) and CYP3A5 (6MJM) were conducted. Results: Michaelis constants $\left(K_{\mathrm{m}}\right)$ for CYP3A5mediated $6 \beta$-hydroxylation of testosterone and progesterone were approximately twice those for CYP3A4, whereas the value for cortisol $6 \beta$-hydroxylation mediated by CYP3A5 was similar to the value for that by CYP3A4. Maximal velocities $\left(V_{\max }\right)$ of the three steroid hormones $6 \beta$-hydroxylation catalyzed by CYP3A5 were $30 \%-63 \%$ of those by CYP3A4. Thus, $V_{\max } / K_{\mathrm{m}}$ values of these hormones for CYP3A5 resulted in 22\%$31 \%$ of those for CYP3A4. The differences in the docking energies between CYP3A4 and CYP3A5 for steroid hormones were slightly correlated to the logarithm of CYP3A5/CYP3A4 ratios for $K_{\mathrm{m}}$ values (substrate affinity). Conclusions: The $V_{\max }$, rather than $K_{\mathrm{m}}$ values, for CYP3A5-mediated 6 $\beta$-hydroxylation of three steroid hormones were different from those for CYP3A4. Molecular docking simulations could partially explain the differences in the accessibility of substrates to the heme moiety of human CYP3A molecules, resulting in the enzymatic affinity of CYP3A4 and CYP3A5.
\end{abstract}

\section{INTRODUCTION}

Cytochrome P450 (P450 or CYP) 3A is the most important human $\mathrm{P} 450$ subfamily, due to its high abundance in the human hepatic microsomes, which accounts for approximately $30 \%$ of total P450s enzymes $(1,2)$. Furthermore, CYP3A enzymes are responsible for $50 \%$ of all pharmaceuticals oxidation (3). Inducible CYP3A4 is generally recognized as the predominant CYP3A form expressed in human livers and intestines. On the other hand, polymorphically expressed CYP3A5 contributes as much as $50 \%$ of hepatic CYP3A in a third of Caucasians and about half of African-Americans (4). It was thought that the substrate specificity of CYP3A5 is similar to that of CYP3A4, because CYP3A4 and CYP3A5 are 83\% homologous in terms of amino acid sequences. However, some differences in catalytic properties have been reported $(5,6)$. We previously reviewed the reported values for (a) Michaelis-Menten constants $\left(K_{m}\right)$, maximal velocities $\left(V_{\max }\right)$, and intrinsic clearance $\left(\mathrm{CL}_{\text {int }}\right.$, $V_{\max } / K_{m}$ ) values for reactions mediated by CYP3A4 and/or CYP3A5, (b) inhibition constants $\left(K_{\mathrm{i}}\right)$ and $50 \%$ inhibitory concentrations $\left(\mathrm{IC}_{50}\right)$, and (c) maximum inactivation rate constants $\left(k_{\text {inact }}\right)$, and demonstrated that the substrate specificities of CYP3A4 and CYP3A5 generally overlap, but some differences can be identified. $(7,8)$.

It is well established that some steroid hormones are metabolized by not only steroidogenic P450s, such as CYP11B1, CYP11B2, CYP17A1, CYP19A1,

Corresponding Author: Prof. Toshiro Niwa, PhD, School of Pharmacy, Shujitsu University, 1-6-1 Nishigawara, Naka-ku, Okayama 703-8516, Japan; E-mail: tniwa@shujitsu.ac.jp 
CYP27A1, but also by drug-metabolizing P450s including CYP2C, CYP2D, and the CYP3A subfamily $(9,10)$. In terms of hydroxylation at the C6 $\beta$ position, testosterone $6 \beta$-hydroxylation is predominantly catalyzed by the CYP3A subfamily $(9,10)$ and is recommended as a preferred reaction of CYP3A4/5 for in vitro experiments in the guidelines for new drug applications regarding in vitro studies of drug metabolism and drug-drug interactions regulated by the US Food and Drug Administration (FDA), European Medicines Agency (EMA), and Japanese Ministry of Health, Labour and Welfare (11-13). The ratio of $6 \beta$-hydroxycortisol to cortisol, a stress hormone, in plasma or urine has been used as an in vivo endogenous marker of CYP3A4/5 metabolic activity (14-16). Progesterone is hydroxylated by drug-metabolizing $\mathrm{P} 450 \mathrm{~s}$ including CYP2D6 and CYP3A4 at the C2 $\beta, \mathrm{C} 6 \alpha$, $\mathrm{C} 6 \beta, \mathrm{C} 16 \alpha$, and $\mathrm{C} 21$ positions, as well as by the steroidogenic CYP21A1 at the C21 position $(9,10)$. However, there are few reports that compare, in detail, the kinetic parameters for the hydroxylation of these steroid hormones mediated by CYP3A4 and CYP3A5.

We previously conducted docking simulation studies for substrates and inhibitors of $\mathrm{P} 450$ proteins, including CYP3A4 and CYP3A5, and demonstrated that some of the results were consistent with the enzymatic characteristics observed in in vitro studies, although the primary sequence of CYP3A5 was aligned with that of CYP3A4 using threedimensional modeling software $(17,18)$.

In the present study, we compared the CYP3A4 and CYP3A5-mediated 6 $\beta$-hydroxylation of three steroid hormones: testosterone, progesterone, and cortisol. In addition, we carried out docking simulations for the binding of CYP3A4 and CYP3A5 with steroid hormones using a docking simulation program and compared the results with previously reported compounds (18). We report herein that the differences in accessibility of substrates to the heme of human CYP3A molecules resulted in the apparent enzymatic affinity of CYP3A4 and CYP3A5.

\section{MATERIALS AND METHODS}

\section{Materials}

CYP3A4 and CYP3A5 expressed in recombinant Escherichia coli (Bactosomes) were obtained from Cypex Ltd (Dundee, UK). Testosterone and cortisol were purchased from Nakarai Tesque (Kyoto, Japan) and Fujifilm Wako Pure Chemicals (Osaka, Japan), respectively. Metabolites $6 \beta$-hydroxytestosterone and $6 \beta$-hydroxycortisol were obtained from SigmaAldrich (St Louis, MO, USA). Progesterone and $6 \beta$ hydroxyprogesterone were purchased from Tokyo Chemical Industry (Tokyo, Japan) and Steraloids Inc. (Newport, RI USA), respectively. All other reagents and organic solvents used were of the highest purity commercially available.

\section{Hydroxylation Activities of Steroid Hormones}

Testosterone and progesterone $6 \beta$-hydroxylation activities were determined as described previously with minor modification (19-22). The incubation mixtures consisted of $10 \mathrm{pmol} / \mathrm{mL}$ CYP3A4 or CYP3A5, $1 \mathrm{mM} \mathrm{NADPH}$, and $100 \mathrm{mM}$ potassium phosphate buffer ( $\mathrm{pH} 7.4)$ in a final volume of 0.5 $\mathrm{mL}$. Incubation times were $5 \mathrm{~min}$, with the exception of cortisol $6 \beta$-hydroxylation by CYP3A4 (10 min) or CYP3A5 (20 min). For the $6 \beta$-hydroxycortisol assay, the reaction was terminated by adding $3.5 \mathrm{~mL}$ of ethyl acetate. The organic phase $(3 \mathrm{~mL})$ was evaporated and the residue was immediately dissolved in $200 \mu \mathrm{L}$ of $5 \mathrm{mM} \mathrm{KH} \mathrm{KH}_{4} /$ methanol (75:25). HPLC analysis was performed by injecting $50 \mu \mathrm{L}$ into an Inertsil ODS- 3 column $(150 \times 4.6 \mathrm{~mm}$ I.D., GL Sciences Inc.), with the column temperature set at $40{ }^{\circ} \mathrm{C}$. The UV-detector was set at $240 \mathrm{~nm}$.

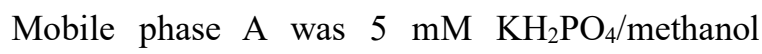
(75:25) and mobile phase $\mathrm{B}$ was $5 \mathrm{mM}$ $\mathrm{KH}_{2} \mathrm{PO}_{4} /$ methanol $(20: 80)$. A gradient elution at a flow rate of $1 \mathrm{~mL} / \mathrm{min}$ was performed as follows: 015 min $0 \%$ B, 15-16 min 0-100\% B (linear gradient), 16-25 min $100 \%$ B, 25-26 min 100-0\% B (linear gradient), and $26-40 \mathrm{~min} 35 \% \mathrm{~B}$. Calibration curves were linear for $6 \beta$-hydroxycortisol concentrations ranging from 0.1 to $5 \mu \mathrm{M}$.

All data were analyzed using the average of triplicate determinations. In the preliminary experiments, the linearity of the reaction with P450 
concentration and incubation time was confirmed for each CYP3A subfamily. $K_{\mathrm{m}}$ and $V_{\max }$ values were calculated by performing Michaelis-Menten kinetics using nonlinear least squares regression by means of MULTI (23).

\section{Docking Simulation of Steroid Hormones with Human P450 Enzymes}

The crystal structures of CYP3A4 (Protein Data Bank code ITQN) and CYP3A5 (6MJM) were used $(24,25)$. Prior to the docking simulations, the energies of the CYP3A4 and CYP3A5 structures were minimized using the CHARMM22 force field. Docking simulations were carried out for the binding of substrates to P450 enzymes using the MMFF94x force field distributed in the Molecular Operating Environment (MOE) ASEDock software (Chemical Computing Group, Montreal, Canada) (18). Twenty solutions were generated for each docking experiment and then ranked according to total interaction energy ( $U$ value).

\section{Literature Search for Kinetic Parameters}

For the correlation analysis, kinetic parameters such as $K_{m}, V_{\max }$, and $V_{\max } / K_{m}$ for several compounds, including estradiol and estrone, were obtained from the literature $(10,18,26)$. Correlation analysis was carried out using Prism (GraphPad Software, La Jolla, CA).

\section{RESULTS}

The kinetic parameters for the $6 \beta$-hydroxylation of three steroid hormones by CYP3A4 and CYP3A5 were estimated by fitting the values into the Michaelis-Menten plots (Table 1). The $K_{\mathrm{m}}$ values for CYP3A5-mediated 6 $\beta$-hydroxylation of testosterone and progesterone were approximately twice those for CYP3A4, whereas the value for cortisol $6 \beta$ hydroxylation by CYP3A5 was similar to that of CYP3A4. The $V_{\max }$ values for CYP3A5-mediated $6 \beta$-hydroxylation of the three steroid hormones were $30-63 \%$ of those for CYP3A4. Thus, $V_{\max } / K_{\mathrm{m}}$ values for the $6 \beta$-hydroxylation of these hormones by CYP3A5 were $22-31 \%$ of those for CYP3A4. For both CYP3A4 and CYP3A5, $K_{\mathrm{m}}$ values for progesterone were lowest, followed by testosterone. $V_{\max }$ values for testosterone were highest among the three steroid hormones, and $V_{\max } / K_{\mathrm{m}}$ values for cortisol were lowest.

Molecular docking simulations were conducted on six steroid hormones with CYP3A4 and CYP3A5 (Table 2). For estrone, the $K_{\mathrm{m}}$ value for CYP3A5mediated 4-hydroxylation is reported to be higher than that for CYP3A4 $(10,26)$. As such, ligand-P450 interaction energies ( $U$ values) were found to be lower for CYP3A4 than for CYP3A5. However, $U$ values for CYP3A5 in other steroid hormones were lower than those for CYP3A4. In all cases, the docking distance was between 3.82 and $11.3 \AA$. Several compounds, other than these steroid hormones, were investigated in order to confirm the present docking results.

Table 1. Kinetic parameters for steroid 63-hydroxylation activities by recombinant human CYP3A4 and CYP3A5

\begin{tabular}{llccc}
\hline Steroid & CYP3A4/5 & $\begin{array}{c}K_{\mathrm{m}} \\
(\mu \mathrm{M})\end{array}$ & $\begin{array}{c}V_{\max } \\
(\mathrm{nmol} / \mathrm{min} / \mathrm{nmol} \mathrm{CYP3A})\end{array}$ & $\begin{array}{c}V_{\max } / K_{\mathrm{m}} \\
(\mathrm{mL} / \mathrm{min} / \mathrm{nmol} \mathrm{CYP3A})\end{array}$ \\
\hline Testosterone & CYP3A4 & $63.8 \pm 10.5(100)$ & $125 \pm 7(100)$ & $1.96(100)$ \\
& CYP3A5 & $119 \pm 24(186)$ & $51.1 \pm 4.1(41)$ & $0.43(22)$ \\
\hline Progesterone & CYP3A4 & $14.3 \pm 2.7(100)$ & $43.4 \pm 1.6(100)$ & $3.03(100)$ \\
& CYP3A5 & $29.2 \pm 3.6(204)$ & $27.2 \pm 0.8(63)$ & $0.93(31)$ \\
\hline Cortisol & CYP3A4 & $358 \pm 37(100)$ & $12.2 \pm 0.5(100)$ & $0.034(100)$ \\
& CYP3A5 & $413 \pm 136(115)$ & $3.6 \pm 0.5(30)$ & $0.007(26)$ \\
\hline
\end{tabular}

Kinetic parameters were determined by nonlinear regression analysis (mean \pm standard deviation, $\mathrm{n}=7$ substrate concentrations in the range of $2-1,000 \mu \mathrm{M}$, in triplicate determinations). Values in parentheses are percentage of those for CYP3A4. 
Vincristine, which is a typical substrate of CYP3A5 and has higher $V_{\max }$ and $V_{\max } / K_{m}$ values and a lower $K_{m}$ value for reactions mediated by CYP3A 5 than by CYP3A4 (27), could more closely dock to the heme

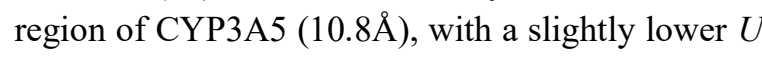
value, than to that of CYP3A4 (18.5 $\AA$ ). $\beta$ Endosulfan, which has a lower $K_{m}$ value and higher $V_{\max }$ and $V_{\max } / K_{m}$ values for reactions mediated by CYP3A5 than by CYP3A4 (28), had a lower $U$ value for CYP3A5 than for CYP3A4. On the other hand, midazolam 1'- and 4-hydroxylations which have higher $K_{m}$ and $V_{\max }$ values for reactions catalyzed by CYP3A4 than by CYP3A5 $(8,18)$, had a lower $U$ value for CYP3A4 than that for CYP3A5.

We investigated the relationship between the ratios of mean $K_{\mathrm{m}}, V_{\max }$, and $V_{\max } / K_{\mathrm{m}}$ values obtained in the present study and previously reviewed for CYP3A4 and CYP3A5 (18), and the differences between the $U$ values for these P450s (Fig. 1). The difference in $U$ values between CYP3A5 and CYP3A5 were slightly correlated with the logarithm of CYP3A5/CYP3A4 ratios for $K_{\mathrm{m}}(r=0.62, p=$ 0.14 , Fig. $1 \mathrm{~A})$ and $V_{\max }$ values $(r=0.64, p=0.12$, Fig. 1B), but not with the logarithm of
CYP3A5/CYP3A4 ratios for $V_{\max } / K_{\mathrm{m}}$ values (Fig. 1C). $U$ : interaction energy in $\mathrm{kcal} / \mathrm{mol}$. Seven reactions of five steroid hormones as shown in Table 2, except for DHEA, were investigated. Dotted lines show the regression curve between the logarithm of the CYP3A5/CYP3A4 ratios of $K_{\mathrm{m}}, V_{\max }$, and $V_{\max } / K_{\mathrm{m}}$ values and the differences between $U$ values for CYP3A4 and CYP3A5 for steroid hormones.

\section{DISCUSSION}

Testosterone $6 \beta$-hydroxylation is recommended as a preferred reaction of CYP3A4/5 for in vitro experiments (11-13) and the 6 $\beta$ hydroxycortisol/cortisol ratio is used as an in vivo endogenous marker of CYP3A4/5 metabolic activities (14-16). In addition, cortisol, a stress hormone, is known to be one of the many hormones responsible for the physiological changes involved in response to stress, as well as a glucocorticoid hormone that is produced by the adrenal glands and released for a variety of reasons (29). Progesterone 6 $\beta$-hydroxylation is catalyzed by drug-metabolizing P450s, including CYP3A4 and CYP2D6 $(9,10)$.

Table 2. Docking simulation results of steroid hormones with respect to human CYP3A4 and CYP3A5

\begin{tabular}{|c|c|c|c|c|c|}
\hline \multirow[b]{2}{*}{ Compound } & \multirow[b]{2}{*}{ Reaction } & \multicolumn{2}{|c|}{$U$ value $(\mathrm{kcal} / \mathrm{mol})$} & \multicolumn{2}{|c|}{ Distance $(\AA)$} \\
\hline & & CYP3A4 & CYP3A5 & CYP3A4 & CYP3A5 \\
\hline Testosterone & $6 \beta$-Hydroxylation & -26.3 & -38.5 & 5.03 & 7.36 \\
\hline Progesterone & $6 \beta$-Hydroxylation & -11.8 & -34.7 & 10.7 & 11.3 \\
\hline Cortisol & $6 \beta$-Hydroxylation & -27.0 & -44.7 & 6.65 & 6.99 \\
\hline \multirow[t]{2}{*}{ DHEA } & $7 \beta$-Hydroxylation & -27.6 & -39.0 & 8.31 & 8.22 \\
\hline & 16a-Hydroxylation & -30.4 & -41.8 & 5.68 & 6.03 \\
\hline \multirow[t]{2}{*}{ Estradiol } & 2-Hydroxylation & $-5.7(18)$ & -18.8 & 9.27 & 7.24 \\
\hline & 4-Hydroxylation & $-5.7(18)$ & -18.8 & 9.21 & 7.62 \\
\hline \multirow[t]{2}{*}{ Estrone } & 2-Hydroxylation & -38.0 & -20.7 & 4.04 & 7.65 \\
\hline & 4-Hydroxylation & -38.0 & -20.7 & 3.82 & 8.81 \\
\hline Vincristine & M1 formation & $-17.8(18)$ & -20.6 & 18.5 & 10.8 \\
\hline$\beta$-Endosulfan & Sulfate formation & $-7.17(18)$ & -21.1 & 5.77 & 9.92 \\
\hline \multirow[t]{2}{*}{ Midazolam } & 1'-Hydroxylation & $-52.3(18)$ & -26.0 & 4.64 & 4.71 \\
\hline & 4-Hydroxylation & $-52.3(18)$ & -24.0 & 5.31 & 4.52 \\
\hline
\end{tabular}

DHEA: dehydroepiandrosterone. 


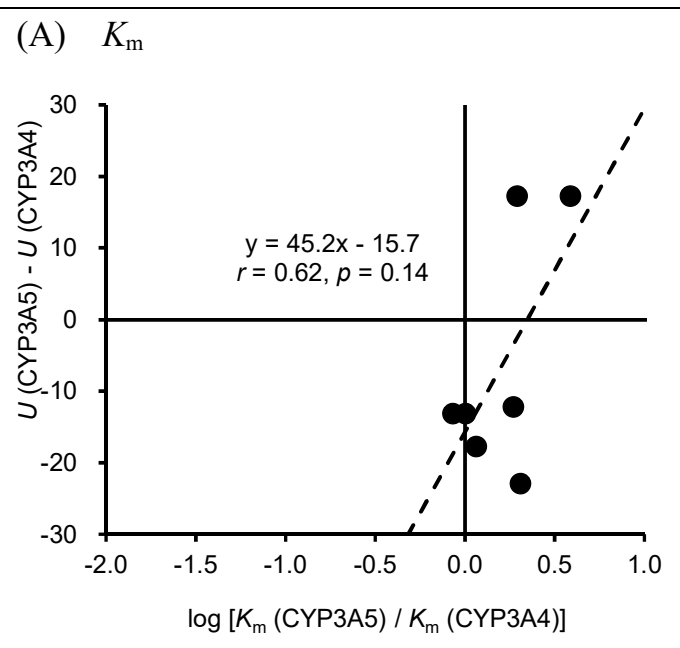

(B) $V_{\max }$

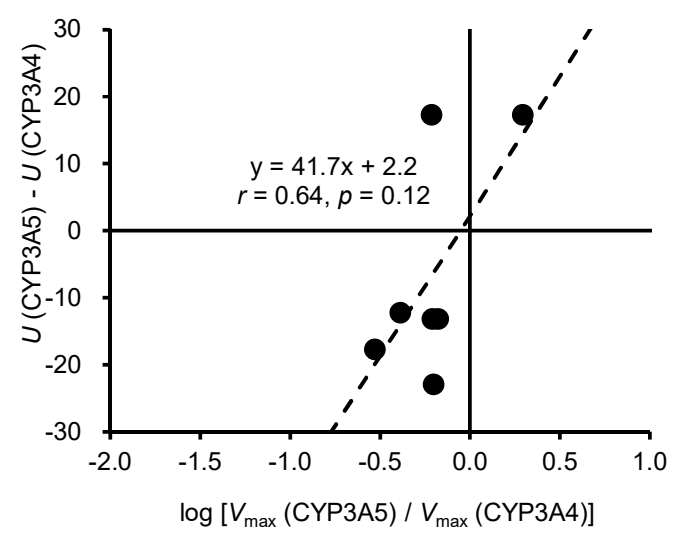

(C) $V_{\max } / K_{\mathrm{m}}$

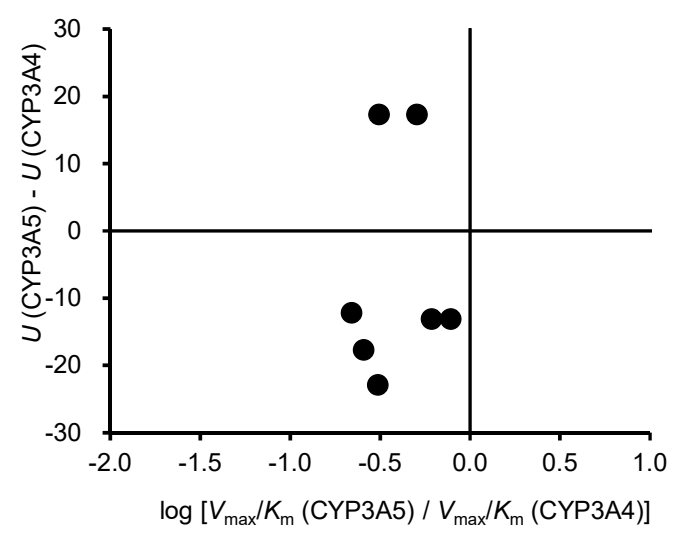

Figure 1. Relationship between the ratios of $K_{\mathrm{m}}(\mathrm{A}), V_{\max }$ (B), and $V_{\max } K_{\mathrm{m}}(\mathrm{C})$, and the differences between docking energy values for CYP3A4 and CYP3A5. $U$ : interaction energy in $\mathrm{kcal} / \mathrm{mol}$. Seven reactions of five steroid hormones as shown in Table 2, except for DHEA, were investigated. Dotted lines show the regression curve between the logarithm of the CYP3A5/CYP3A4 ratios of $K_{\mathrm{m}}, V_{\max }$, and $V_{\max } / K_{\mathrm{m}}$ values and the differences between $U$ values for CYP3A4 and CYP3A5 for steroid hormones.
Although $K_{\mathrm{m}}$ and $V_{\max }$ values for testosterone $6 \beta$ hydroxylation by recombinant CYP3A4 and/or CYP3A5 have already been reported as $24-110 \mu \mathrm{M}$ (for CYP3A4) and 44-400 $\mu \mathrm{M}$ (for CYP3A5) for $K_{\mathrm{m}}$ values and $3.8-3600 \mathrm{nmol} / \mathrm{min} / \mathrm{nmol} \mathrm{P} 450$ (for CYP3A4) and 2.2-1600 nmol/min $/ \mathrm{P} 450$ (for CYP3A5) for $V_{\max }$ values $(7,10,30-36)$, the values obtained in the present study $\left(K_{\mathrm{m}}: 63.8 \mu \mathrm{M}\right.$ for CYP3A4 and $119 \mu \mathrm{M}$ for CYP3A5, $V_{\max }: 125$ $\mathrm{nmol} / \mathrm{min} / \mathrm{nmol} \mathrm{P} 450$ for CYP3A4 and 51.1 $\mathrm{nmol} / \mathrm{min} / \mathrm{nmol} \mathrm{P} 450$ for CYP3A5) were similar to the medians of the reported values. In the present study, $K_{\mathrm{m}}$ values for $6 \beta$-hydroxylation of three steroid hormones (testosterone, progesterone, and cortisol) mediated by CYP3A5 were at most twice those for the CYP3A4-mediated reactions, whereas $V_{\max }$ values for the hydroxylation catalyzed by CYP3A5 were $30-63 \%$ of those for CYP3A4. Therefore, $V_{\max } / K_{\mathrm{m}}$ values, which correspond to intrinsic clearance, for the hydroxylation of these hormones by CYP3A5 were $22-31 \%$ of those for CYP3A4. These results suggest that testosterone $6 \beta$ hydroxylation activity in human liver microsomes for in vitro studies of drug-drug interactions would depend on the CYP3A4 level rather than CYP3A5. Thus, the addition of other substrates, such as midazolam, might be necessary for the assessment of CYP3A4/5 activity as recommended by FDA and PMDA $(11,13)$. Furthermore, the effect of CYP3A5 polymorphism on the plasma or urine ratio of $6 \beta$ hydroxycortisol/cortisol in vivo as a marker for stress might be of minor importance. Further clinical studies are necessary to elucidate the problem.

We previously carried out docking simulations for the binding of CYP3A4 and CYP3A5 with 13 substrates using docking simulation program MOE and found that the docking energy ratio between CYP3A5 and CYP3A4 were not significantly correlated with the CYP3A5/CYP3A4 ratios of $V_{\max }$ and $V_{\max } / K_{\mathrm{m}}$ values, nor with molecular weight, volume, or $\log \mathrm{P}$ values of substrates. Furthermore, neither the differences in the enzyme source (baculovirus infected insect cells or Escherichia coli engineered to express P450s) nor the supplementation or co-expression of cytochrome $b_{5}$ were correlated with the $K_{\mathrm{m}}, V_{\max }$, and $V_{\max } / K_{\mathrm{m}}$ values for CYP3A4 or CYP3A5 (18). In our 
previous study, the primary sequence of CYP3A5 was aligned with that of CYP3A4 using threedimensional modeling software (18), while in the present study, we used the recently reported crystal structures of CYP3A5 (Protein Data Bank code 6MJM) (25). Vincristine, a typical substrate of CYP3A5, but not of CYP3A4, has higher $V_{\max }$ and $V_{\max } / K_{m}$ values and a lower $K_{m}$ value for reactions mediated by CYP3A5 than by CYP3A4 (27). In the present study, vincristine was shown to dock closer to the heme region of CYP3A5 (10.81 $)$ with a

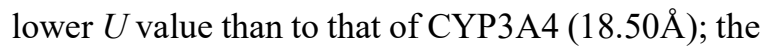
findings were similar to the previous in silico analysis (18). In the case of midazolam, for which $K_{\mathrm{m}}$ value for CYP3A5 was higher than for CYP3A4, the docking energies for CYP3A4 were lower than those for CYP3A5. Although $U$ values for CYP3A5 in steroid hormones, with the exception of estrone, were lower than those for CYP3A4, the difference in $K_{\mathrm{m}}$ values as well as $V_{\max }$ values, but not $V_{\max } / K_{m}$ values and docking results, between CYP3A4 and CYP3A5 for steroid hormones were slightly corelated (Fig. 2). However, because it's highly unlikely that the reaction with higher $V_{\max }$ values would have higher $U$ values, we suggest that molecular docking simulations could partially explain the differences in substrate affinity (the $K_{\mathrm{m}}$ values), as demonstrated in the previous study (18). As CYP3A4 and CYP3A5 are 83\% homologous in terms of amino acid sequences, the most plausible explanation for the differences between CYP3A4 and CYP3A5 is that conformational changes, caused by amino acid differences, lead to altered accessibility of substrates and inhibitors to the heme iron of CYP3A4 and CYP3A5. However, it would be difficult to determine the substrates for which $K_{\mathrm{m}}$ and $V_{\max }$ values for CYP3A5 are different from those for CYP3A4, by using the differences in $U$ values (18). Further quantitative analytical studies with additional substrates and inhibitors, including those with a preference for either CYP3A4 or CYP3A5, are required. In the future, more advanced simulations such as molecular dynamics simulations are of interest, in order to explain the induced-fit effects caused by different ligands binding.

In conclusion, $V_{\max }$ values, rather than $K_{\mathrm{m}}$ values, for $6 \beta$-hydroxylation of three steroid hormones by
CYP3A5 were different from those for CYP3A4, and molecular docking simulations might partially explain the differences in the affinity of substances for CYP3A4 and CYP3A5, based on the accessibility of substrates to the heme moiety of CYP3A molecules.

\section{ACKNOWLEDGEMENTS}

We are grateful to Motohiro Yasumura for his help on docking simulation.

\section{DECLARATION OF INTEREST}

The authors report no conflicts of interest. The authors alone are responsible for the content and writing of the paper.

\section{REFERENCES}

1. Shimada T, Yamazaki H, Mimura M, Inui $Y$, Guengerich FP. Interindividual variation in human liver cytochrome P-450 enzymes involved in the oxidation of drugs, carcinogens and toxic chemicals: Studies with liver microsomes of 30 Japanese and 30 Caucasians. J Pharmacol Exp Ther, 1994; 270: 414-423.

2. Imaoka S, Yamada T, Hiroi T, Hayashi K, Sakaki T, Yabusaki Y, Funae Y. Multiple forms of human P450 expressed in Saccharomyces cerevisiae. Systematic characterization and comparison with those of the rat. Biochem Pharmacol. 1996; 51: 1041-1050.

3. Williams JA Hyland R, Jones BC, Smith DA, Hurst S, Goosen TC, Peterkin V, Koup JR, Ball SE. Drugdrug interactions for UDP-glucuronosyltransferase substrates: a pharmacokinetic explanation for typically observed low exposure (AUCi/AUC) ratios. Drug Metab Dispos. 2004; 32: 1201-1208.

4. Kuehl P, Zhang J, Lin Y, Lamba J, Assem M, Schuetz J, Watkins PB, Daly A, Wrighton SA, Hall SD, Maurel P, Relling M, Brimer C, Yasuda K, Venkataramanan R, Strom S, Thummel K, Boguski MS, Schuetz E. Sequence diversity in CYP3A promoters and characterization of the genetic basis of polymorphic CYP3A5 expression. Nat Genet. 2001; 27: 383-391.

5. de Wildt SN, Kearns GL, Leeder JS, van den Anker JN. Cytochrome P450 3A: ontogeny and drug disposition. Clin Pharmacokinet, 1999; 37: 485-505.

6. Daly AK. Significance of the minor cytochrome P450 3A isoforms. Clin Pharmacokinet. 2006; 45: 13-31. 
7. Niwa T, Murayama N, Emoto C, Yamazaki, H. Comparison of kinetic parameters for drug oxidation rates and substrate inhibition potential mediated by cytochrome P450 3A4 and 3A5. Curr Drug Metab. 2008; 9: 20-33.

8. Niwa T, Murayama N, Yamazaki H. Comparison of the contributions of cytochrome P450 3A4 and 3A5 in drug oxidation rates and substrate inhibition. $\mathrm{J}$ Health Sci. 2010; 56: 239-256.

9. Rendic S. Summary of information on human CYP enzymes: human P450 metabolism data. Drug Metab Rev. 2002; 34: 83-448.

10. Niwa T, Murayama N, Imagawa Y, Yamazaki H. Regioselective hydroxylation of steroid hormones by human cytochromes P450. Drug Metab Rev. 2015; 47: 89-110. DOI: 10.3109/03602532.2015.1011658.

11. U.S. Food and Drug Administration. Drug Development and Drug Interactions: Table of Substrates, Inhibitors and Inducers. http://www.fda.gov/Drugs/DevelopmentApprovalP rocess/DevelopmentResources/DrugInteractionsLa beling/ucm093664.htm\#4 (27 October 2014)

12. European Medicines Agency. Guideline on the investigation of drug interactions. 6/21/2012. CPMP/EWP/560/95/Rev. 1 Corr. 2**. http://www.ema.europa.eu/docs/en_GB/document library/Scientific_guideline/2012/07/WC50012960 6.pdf\#search='European+Medicines + Agency\%2C + drug+interaction' (21 June 2012)

13. Pharmaceuticals and Medical Devices Agency. Methods of drug interaction studies (PMSB/ELD Notification No. 813; June 4, 2001). http://www.nihs.go.jp/phar/pdf/DiGlEngFinal0112 09.pdf. (4 June 2001)

14. Galteau MM, Shamsa F. Urinary 6 6 hydroxycortisol: a validated test for evaluating drug induction or drug inhibition mediated through CYP3A in humans and in animals. Eur $\mathrm{J}$ Clin Pharmacol. 2003; 59: 713-733.

15. Peng CC, Templeton I, Thummel KE, Davis C, Kunze KL, Isoherranen N. Evaluation of $6 \beta$ hydroxycortisol, 6 6 -hydroxycortisone, and a combination of the two as endogenous probes for inhibition of CYP3A4 in vivo. Clin Pharmacol Ther. 2011; 89: 888-895. DOI: 10.1038/clpt.2011.53.

16. Rais N, Chawla YK, Kohli KK. CYP3A phenotypes and genotypes in North Indians. Eur J Clin Pharmacol. 2006; 62: 417-422.

17. Okada Y, Murayama N, Yanagida C, Shimizu M, Guengerich FP, Yamazaki H. Drug interactions of thalidomide with midazolam and cyclosporine A: heterotropic cooperativity of human cytochrome P450 3A5. Drug Metab. Dispos. 2009; 37: 18-23. DOI: 10.1124/dmd.108.024679.

18. Niwa T, Yasumura M, Murayama N, Yamazaki H. Comparison of catalytic properties of cytochromes
P450 3A4 and 3A5 by molecular docking simulation. Drug Metab Lett. 2014; 8: 43-50.

19. Hiroi T, Kishimoto W, Chow T, Imaoka S, Igarashi T, Funae Y. Progesterone oxidation by cytochrome P450 2D isoforms in the brain. Endocrinology. 2001; 142: 3901-3908.

20. Niwa T, Hiroi T, Tsuzuki D, Yamamoto S, Narimatsu S, Fukuda T, Azuma J, Funae Y. Effect of genetic polymorphism on the metabolism of endogenous neuroactive substances, progesterone and $p$-tyramine, catalyzed by CYP2D6. Mol Brain Res. 2004; 129: 117-123.

21. Niwa T, Inoue S, Shiraga T, Takagi A. No inhibition of cytochrome $\mathrm{P} 450$ activities in human liver microsomes by sulpiride, an antipsychotic drug. Biol Pharm Bull. 2005; 28: 188-191.

22. Niwa T, Morimoto M, Hirai T, Hata T, Hayashi M, Imagawa Y. Effect of penicillin-based antibiotics, amoxicillin, ampicillin, and piperacillin, on drugmetabolizing activities of human hepatic cytochromes P450. J Toxicol Sci. 2016; 41: 143-146. DOI: $10.2131 /$ jts.41.143.

23. Yamaoka K, Tanigawara Y, Nakagawa T, Uno T, A pharmacokinetic analysis program (multi) for microcomputer, J Pharmacobiodyn. 1981; 4: 879885.

24. Yano JK, Wester MR, Schoch GA, Griffin KJ, Stout $\mathrm{CD}$, Johnson EF. The structure of human microsomal cytochrome P450 3A4 determined by $\mathrm{X}$-ray crystallography to $2.05-\mathrm{A}$ resolution. J Biol Chem. 2004; 279: 38091-38094.

25. Hsu MH, Johnson EF. Active site differences between substrate-free and ritonavir-bound cytochrome P450 (CYP) 3A5 reveal plasticity differences between CYP3A5 and CYP3A4. J Biol Chem. 2019;294:8015-8022. DOI: 10.1074/jbc.RA119.007928.

26. Lee AJ, Cai MX, Thomas PE, Conney AH, Zhu BT. Characterization of the oxidative metabolites of $17 \beta$-estradiol and estrone formed by 15 selectively expressed human cytochrome P450 isoforms. Endocrinology. 2003; 144: 3382-3398.

27. Dennison JB, Kulanthaivel P, Barbuch RJ, Renbarger JL, Ehlhardt WJ, Hall SD. Selective metabolism of vincristine in vitro by CYP3A5. Drug Metab Dispos. 2006; 34: 1317-1327.

28. Lee HK, Moon JK, Chang CH, Choi H, Park HW, Park BS, Lee HS, Hwang EC, Lee YD, Liu KH, Kim JH. Stereoselective metabolism of endosulfan by human liver microsomes and human cytochrome P450 isoforms. Drug Metab Dispos. 2006; 34: 1090-1095.

29. Thau L, Sharma S. Physiology, Cortisol. StatPearls [Internet]. Treasure Island (FL): StatPearls Publishing; 2019 Jan-.2019 Feb 15.

30. Williams JA, Ring BJ, Cantrell VE, Jones DR, Eckstein J, Ruterbories K, Hamman MA, Hall SD, 
Wrighton SA. Comparative metabolic capabilities of CYP3A4, CYP3A5, and CYP3A7. Drug Metab. Dispos. 2002; 30: 883-891.

31. Huang W, Lin YS, McConn DJ $2^{\text {nd }}$, Calamia JC, Totah RA, Isoherranen N, Glodowski M, Thummel KE. Evidence of significant contribution from CYP3A5 to hepatic drug metabolism. Drug Metab. Dispos. 2004; 32: 1434-1445.

32. Patki $\mathrm{KC}$, Von Moltke LL, Greenblatt DJ. In vitro metabolism of midazolam, triazolam, nifedipine, and testosterone by human liver microsomes and recombinant cytochromes P450: role of CYP3A4 and CYP3A5. Drug Metab. Dispos. 2003; 31: 938944.

33. Emoto C, Iwasaki K. Comparison of kinetic parameters for drug oxidation rates and substrate inhibition potential mediated by cytochrome P450
3A4 and 3A5. Curr Drug Metab. 2008; 9: 20-33.

34. Carr B, Norcross R, Fang Y, Lu P, Rodrigues AD, Shou M, Rushmore T, Booth-Genthe C. Characterization of the rhesus monkey CYP3A64 enzyme: species comparisons of CYP3A substrate specificity and kinetics using baculovirus-expressed recombinant enzymes. Drug Metab Dispos. 2006; 34: 1703-1712.

35. Granfors MT, Wang JS, Kajosaari LI, Laitila J, Neuvonen PJ, Backman JT. Differential inhibition of cytochrome P450 3A4, 3A5 and 3A7 by five human immunodeficiency virus (HIV) protease inhibitors in vitro. Basic Clin Pharmacol Toxicol. 2006; 98: 79-85.

36. Walsky RL, Obach RS. Validated assays for human cytochrome P450 activities. Drug Metab Dispos. 2004; 32: 647-660. 